\title{
Commentary on "Surgical technique used in the UK for native tissue anterior pelvic organ prolapse repair (VaST)"
}

\author{
Abdelmageed Abdelrahman ${ }^{1}$ \\ Received: 5 November 2019 / Accepted: 12 November 2019 / Published online: 7 December 2019 \\ (C) The International Urogynecological Association 2019
}

"Surgical technique used in the UK for native tissue anterior pelvic organ prolapse repair (VaST)" by Fairclough et al. [1] is a prospective qualitative study using a purposive sampling strategy to recruit surgeons. A total of 21 urogynaecology centres in the UK were involved in the study. The authors collected data using video-recorded observations of surgery, audio-recorded interviews with surgeons and field-notes.

In total, 30 consultants were recruited. All steps of the native anterior colporrhaphy were described including the method of infiltration, incision, dissection, fascial repair methods, skin trimming, skin closure and surgical terminology regarding native tissue anterior pelvic organ prolapse repair for each of the recruited consultants.

The authors concluded that there is a variety of surgical techniques involved in performing native anterior repairs. Importantly, there also existed a difference in the terminologies used, for example, the term "fascia" was differently utilized.

Strengths of this study include using qualitative methods that allow for a greater understanding of surgical technique used in anterior colporrhaphy. There was a good sample size of 30 consultants with a demographic spread across the UK. Additionally, use of video observations and interviews provides an excellent insight, which is not easily achieved from questionnaires or interviews alone. A limitation of the study includes one visit per site owing to geographical logistics. An advantage of multiple visits allows greater exposure to the surgical techniques employed by each consultant.

\section{Compliance with ethical standards}

Conflicts of interest None.

\section{Reference}

1. Fairclough E, Segar J, Myers J, Smith A, Reid F. Surgical technique used in the UK for native tissue anterior pelvic organ prolapse repair (VaST).Int Urogynecol J. 2019; https://doi.org/10.1007/s00192-01904103-8

Publisher's note Springer Nature remains neutral with regard to jurisdictional claims in published maps and institutional affiliations.
Abdelmageed Abdelrahman

abdelmageed@hotmail.co.uk

1 Department of Urogynaecology, Liverpool Women's Hospital NHS Foundation Trust, Liverpool, UK 